\title{
DESIGN, DEVELOPMENT AND CONSTRUCTION OF A LOW COST AUTOMATIC 2 KVA INVERTER SYSTEM
}

\author{
V. A. AKPAN AND THEOPHILOS EWETUMO \\ (Received 6, November 2008; Revision Accepted 18, March 2009)
}

\begin{abstract}
In this work, detailed techniques for the design and construction of a low cost automatic inverter system capable of converting $24 \mathrm{Vdc}$ to $220 \mathrm{Vac} 60 \mathrm{~Hz}$ with a power handling capacity of $2 \mathrm{kVA}$ have been presented with emphasis on the step-up transformer specification. The major modules of the inverter system consist of a driver and switching circuit; an automatic battery charger circuit; a battery voltage level indicator circuit; and a capacitiveinductive filter. Both solid-state and electromechanical relays were employed to provide automatic fast switching capabilities both in the presence or absence of public power supply (PPS) without voltage fluctuations supplied to the loads during the power switching process. Several experiments have been conducted with the automatic inverter system using different equipment with different power requirements. Analysis and results show that the designed and constructed inverter system has negligible output resistance with low power consumption and it is highly suitable for use in experimental and research laboratories as well as in domestic and industrial applications.
\end{abstract}

KEYWORDS: Design and construction; automatic inverter system; automatic battery charger; battery voltage level indicator; driver and switching circuit.

\section{INTRODUCTION}

Incessant power failure is endemic to the power supply system in Nigeria today causing disruptions in almost all spheres of life including research institutions, in particular. Most experiments in our University laboratories and research institutes are not finalized and concluded due to the epileptic nature of our public power supply system. A forwarded research on this issue (dc to ac inverter) will provide a partial or lasting solution to this end if properly harnessed. Moreover, the proposed automatic inverter system will provide an alternative power source to research students and scientists in remotes locations where electricity is not accessible. On recreational grounds, it can be used during tourism, out-door parties and picnics.

An inverter (or dc-to-ac converter) is a device for converting direct current (d.c) into an alternating current (a.c) (Nostrand, 1978). An automatic switching standby source of power supply is in no doubt required, especially, in laboratories for experimental and/or research purposes as well as in household electrical appliances. The quest for an automatic alternative source of power supply to supplement erratic power supply during laboratory experiments and/or research is the rationale behind this automatic inverter system design, development and construction.

Varieties of inverters design have been reported (Nostrand, 1978; Gottles, 1985; Chan and Bowler, 1974 ). The predecessor of the modern solid-state converter was the vibrator power supply and the thyratron inverters but had efficiencies in vicinity of 40 percent (Gottles, 1985). Other types of inverters range from transistor inverters to thyristor switched inverters and scaled down to driven inverters with integrated circuits
(Chan and Bowler, 1974). The more recent types of inverters are two or more transformer coupled inverters, either in series and/or in parallel, to achieve certain goals depending on the applications but the only problem is the short time duration due to its high power consumption during normal operation as a result of the design (Gottles, 1985). The other major problem faced with the above mentioned types of inverters are low efficiency and the inability of the dc energy power restoration (that is, chargers were not included for charging back-up batteries in the presence of public power supply) as well as the inability of the inverter to switch from the dc source to ac in the event of public power restoration. Although recent designs of solar energy to electrical energy converters include battery charging circuits but still lack the power of switching to public power supply (PPS). This work presents a technique for the construction of low cost automatic 2000 Volt-Ampere (2 kVA) inverter systems for use in laboratory and research institutes as well as for domestic and industrial applications.

\section{The Automatic Inverter System Step-Up Transformer Design}

The design and development of the inverter begins with the step-up transformer (T3 of Figure 2) construction. The subsection details the step-up transformer design in general terms (Fitzgerald et al., 1994; Maris, 1980). The desired power rating for the inverter system is 2000 VA (Volt-Amperes). The maximum primary input voltage available from the four batteries connected in both parallel and series, of $12 \mathrm{~V}$ each, is $24 \mathrm{~V}$ dc (direct current). Although the two Solite $\mathrm{N} 200 \mathrm{Z}$ batteries used in this design are rated $12 \mathrm{~V}$

V. A. AKPAN*, Department of Electrical and Computer Engineering, Faculty of Engineering, Aristotle University of Thessaloniki, GR-54124, Thessaloniki,, Greece.

THEOPHILOS EWETUMO, Department of Physics, Federal University of Technology, P.M.B. 704, Akure, Ondo State, Nigeria 
$200 \mathrm{AH}$ each but their measured values were $13.5 \mathrm{~V}$ respectively. The desired maximum secondary output voltage of the inverter is specified at $220 \mathrm{~V}$ (but varies between $220 \mathrm{~V}$ and $240 \mathrm{~V}$ when the batteries are fully charged or when new). The desired frequency is $60 \mathrm{~Hz}$ single phase. The cooling device for the inverter is a direct current $12 \mathrm{~V} 500 \mathrm{~mA}$ suction fan.

\subsection{Output power of the transformer}

$$
\text { Output power }=\mathrm{V}_{\mathrm{s}} \mathrm{I}_{\mathrm{s}} \operatorname{Cos} \theta \text { Watt. }
$$

where $V_{s}=$ Secondary voltage of transformer, $I_{s}=$ Secondary current of transformer and $\cos \theta=$ Power factor.

$$
\text { But } P_{s}=I_{s} V_{s}
$$

For $\mathrm{P}_{\mathrm{s}}=2000 \mathrm{VA}$ and $\mathrm{V}_{\mathrm{s}}=220 \mathrm{~V}$. Using (2), $\mathrm{I}_{\mathrm{s}}=9.1 \mathrm{~A}$. And using (1), with $P_{s}, V_{s}$ and $I_{s}, \cos \theta=0.9$. Substituting the value of $\cos \theta$ into (1), the output power (in Watts) in terms of the power factor is 1802 Watts. Also from (2), the output power rating (in Volt-Ampere) in terms of the power factor is:

Output power (in VA) = $\frac{\text { outputpower }(\text { in Watts })}{\operatorname{Cos} \theta}=\frac{1802}{0.9}=2002 \mathrm{VA}$.

In Mega-Volts Ampere gives $2.002 \times 10^{-3} \mathrm{MVA}$.

\subsection{The transformer core area determination}

The frame size of the transformer is obtained from the transformer equation (Gottles, 1985):

$$
S=0.2 f B_{m} J A_{f e} A_{c u} M V A
$$

where $f=$ frequency, $\quad J=$ current density, $B_{m}=$ maximum flux density, $A_{f e}=$ core area, $A_{c u}=$ area of copper wire and MVA = Mega Volt Ampere rating of the transformer.

But $\mathrm{S}=$ frame size $=\frac{M V A}{3}=\frac{2.002 \times 10^{-3}}{3}=6.673 \times 10^{-4}$.

Moreover, the core area $\left(\mathrm{A}_{\mathrm{fe}}\right)=K_{A} S^{\frac{1}{2}}$

The thermal conductivity coefficient $\left(K_{A}\right)$ for a 2000Watt transformer from the standard table is $2.86 \times 10^{-1}$ (Gottles, 1985). So that from (5), the core area is computed as $A_{f e}=73.88 \approx 75.00 \mathrm{~cm}^{2}$. Hence, $A_{f e}$ $\left(75.00 \mathrm{~cm}^{2}\right)$ is factored to obtain the core dimensions of $5 \mathrm{~cm}$ by $15 \mathrm{~cm}$ which is used for the inverter step-up transformer construction.

\subsection{Voltage per turn}

The voltage per turn is obtained from the equation;

$$
\frac{V}{N}=\frac{f \cdot B_{m} \cdot A_{f e}}{22.0 \times 10^{-1}}
$$

where $\mathrm{f}=$ frequency, $\mathrm{B}_{\mathrm{m}}=$ flux density, $A_{\mathrm{fe}}=$ core area. The material chosen for the magnetic circuit of the transformer is Silicon Steel because of its higher magnetizing quality. Its flux density is between $0.4-0.8$ Tesla (Nadon, 1989). However, for safe operation without saturation, 0.6Tesla is selected for this transformer design.

Thus, if $B_{m}=0.6$ Tesla, $f=60 \mathrm{~Hz}$ and $A_{f e}=75 \mathrm{~cm}^{2}$, then: $\frac{V}{N}=1.02$ Volts per turn.
2.4 Magnitude of the primary turns

Since the Voltage per turn is $1 \mathrm{~V}$, the number of primary turns is calculated from

$$
\frac{V}{N}=\frac{E_{p}}{N_{P}}
$$

where $E_{p}=$ Applied primary voltage from the battery, $N_{p}$ $=$ Number of turns in the primary winding and $\mathrm{N}=24$ turns (minimum)

To reduce heat loss and overloading of the primary coil as well as for improved and high efficiency, the primary coil winding is increased in multiple of 24 . The primary turns used in this design is 72 turns (24 turns $\times 3$ ).

\subsection{Magnitude of the secondary turns}

From $\frac{V}{N}=\frac{E_{s}}{N_{s}}$

where $E_{s}=$ Output Voltage of the inverter and $N_{s}=$ Number of turns in the secondary winding. Although the actual $\mathrm{N}_{\mathrm{s}}=240$ but for safety reasons and for higher efficiency, the secondary coil winding is increased in multiples of $240\left(\mathrm{~N}_{\mathrm{s}}\right)$. The secondary turns in this design is 720 turns ( 240 turns $\times 3$ ).

\subsection{Determination of conductor wire gauge:}

(i) The primary conductor size depends on the current that will flow through it. Thus

$$
I_{p}=\frac{P}{V_{p}}=\frac{2000}{24}=83.33 \text { Amperes }(\max \text { imum })
$$

Choosing from the American table for standard wires gauge (Gottles, 1985), SWG 17(gauge-17) is suitable and has been chosen for this design.

(ii) The secondary conductor size also depends on the current that will flow through it. Thus

$$
I_{s}=\frac{P}{V_{s}}=\frac{2000}{240}=8.33 \text { Amperes }(\max \text { imum })
$$

Again from the American table for standard wires gauge, SWG 25(gauge-25) is suitable and has been chosen for this design.

\subsection{Efficiency of the transformer.}

The resistance of the primary winding is $0.10 \Omega$ and both are copper wires. The heat loss by the secondary winding copper wire is given by: $Q_{s c u}=I_{s}^{2} R_{s}=(8.33)^{2} \times 0.24=16.7$ Watt

The efficiency $(E)$ of the output stage of the transformer is given by (Maris, 1980):

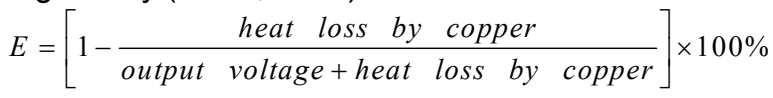

Thus, the efficiency of the transformer is approximately $93.5 \%$.

\section{The Development of the Automatic Inverter System Control Circuits}

\subsection{Overview of the Inverter}

The major modules of the inverter consist of four transformers (two step-down transformers for 
biasing Relay $\mathbf{A}$ and Relay $\mathbf{B}$ respectively, the third is a step-up transformer for the main power inverter while the fourth is a step-down transformer for the battery charger). The driver circuit is made up of the NE555CN (IC4 of Figure 2) configured as an astable multivibrator (square-wave generator) circuit and CMOS TC4027BP (IC5 of Figure 2) configured as a frequency divider circuit as well as a differential amplifier (Coughlin, and Driscoll, 1989) which performs the function of a phasesplitter. The internal structure and mode of operation of NE555CN and CMOS TC4027BP is detailed in (Hall, 1989). Also included in this inverter is a switching circuit which employs eight power enhancement IRF150 MOSFET (Q6-Q13 of Figure 2) transistors (Mottershead, 2005; Franco, 1998). An automatic battery charger circuit built around LM338 (IC6 of Figure 3), a temperature compensation circuit using LM334 (IC7 of Figure 3) and LM308A (IC8 of Figure 3) configured as a comparator also form an integral part of the inverter. The characteristics and operational conditions of LM338, LM334 and LM308A can be found in (Coughlin and Driscoll, 1989; Franco, 1998; Melling, 2004). A battery voltage level indicator circuit is also included for monitoring the battery status whenever the inverter is in operation. A capacitive-inductive filter is also included to smoothen and shape the square-wave from the inverter's output to sine-wave required by virtually all electrical and/or electronic appliances. Diodes D1-D4, D6-D9, and D19-D22 are all type IN5401 power diodes.

The inverter also make use of a solid state and electromechanical relays for automatic switching of the load either to the inverter power output channel or to public power supply, when available, as well as charging the back-up batteries during the availability of public power supply.

\subsection{Block Diagram of the Complete Inverter}

The block diagram of the dc-to-ac inverter and all its sub-circuit is shown in Figure 1 . Relay $\mathbf{A}$ is a $24 \mathrm{~V}$ 400A 11-pin 6-output (3 NC and 3 NO) electromechanical relay and it is driven by the "biasing circuit A" only when PPS is available. Relay B is a $12 \mathrm{~V}$ $10 \mathrm{~A}$ 5-pin 2-output (2 NC and $2 \mathrm{NO}$ ) electromechanical relay and it is driven by the "biasing circuit B" when the driver and switching circuit is in operation. The circuit of transformer T1, diodes D1-D4, voltage regulator IC1 and transistor $\mathrm{Q} 1$ is a biasing circuit $\mathbf{A}$ that triggers Relay $\mathbf{A}$. This circuit is driven only by the public power supply when available. In a similar way, the circuit of transformer T2 down to transistor Q2 is also a biasing circuit that is energized only in the absence of public power supply but provided that switch $\mathbf{B}$ is closed (i.e. the inverter is in use). This circuit drives the cooling suction fan and turns $\mathrm{ON}$ the battery voltage level indicator through Relay $\mathbf{B}$. The remaining three (3) blocks: the driver and switching circuit, the automatic battery charger and the battery voltage level indicator are described in the next two subsequent subsections of this paper.

Relay A plays a significant role in the overall switching of the load between the inverter power output channel and the public power supply. In the presence of the public power supply, Relay $\mathbf{A}$ is triggered (switched $\mathrm{ON}$ and terminal 3 (input, in) is connected to terminal 4 (normally open, NO). At this instance, the load is fed from the public power supply and the batteries are equally charged by the battery charger. In the absence of the public power supply, the relay $\mathbf{A}$ is switched OFF. Thus, terminals 6 (in) and 8 (normally closed, NC) of relay $A$ as well as terminals 9 (in) and 11 (NC) are respectively connected. At this instant, the cooling fan simultaneously switches $\mathrm{ON}$ and the battery voltage level indicator also switched $\mathrm{ON}$ through the NO terminal of Relay $\mathbf{B}$.

If the toggle switch (Switch B) is closed, electrical energy from the batteries flows through terminals 3 (in) and 4 (NC) to the inverter; and immediately the driver and switching is activated which produces an alternating current voltage of $220 \mathrm{~V} 60 \mathrm{~Hz}$. This electrical power is delivered to the load though terminals 9 (in) and 11 (NC) of Relay A (Figure 1).

On the other hand if PPS is available, Relay $\mathbf{A}$ will be switched ON and the electrical power from PPS is delivered directly to the load via terminals $\mathbf{3}$ (in) and $\mathbf{4}$ (NO) of Relay A and the driver and switching circuit is disabled since the batteries link to the driver and switching circuit has been broken by Relay A, i.e. terminal $\mathbf{3}$ is connected to the NO terminal $\mathbf{5}$ (not shown in Figure 1 for clarity). 


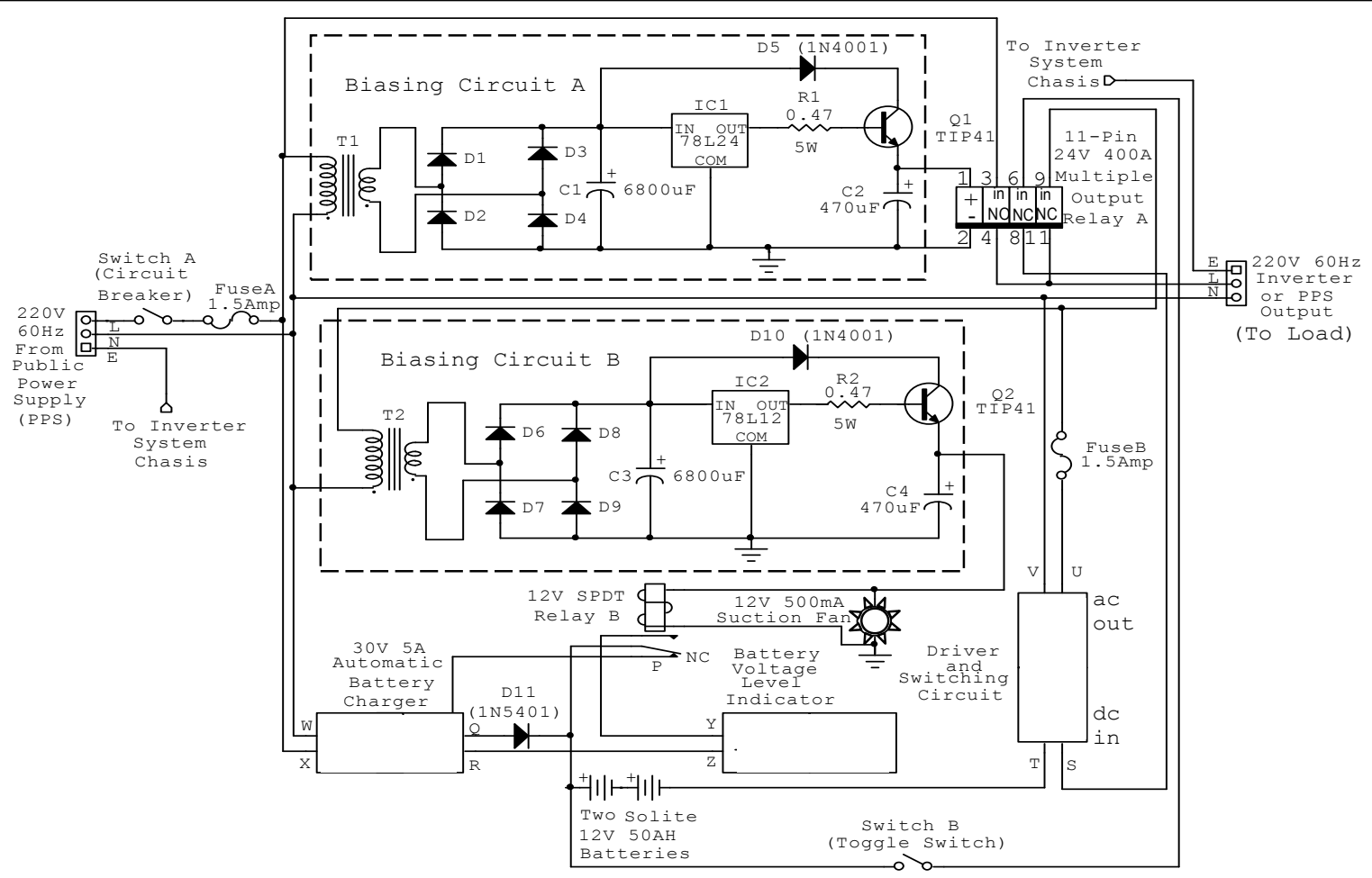

Figure 1: Block diagram of the automatic inverter system.

\subsection{The Driver and Switching Circuit}

The driver and switching circuit is shown in Figure 2. The driver circuit consists of an astable multivibrator built around NE555CN (IC4) wired in the astable mode with an oscillating at a frequency of $120 \mathrm{~Hz}$. The frequency is given by;

$$
f=\frac{1.44}{\left(2 \cdot R_{4+5}+R_{6+7}\right) \cdot C_{8}}
$$

Resistors $\left(R_{4}\right.$ and $\left.R_{5}\right)$ and resistors $\left(R_{6}\right.$ and $\left.R_{7}\right)$ were made of equal values in order to produce a duty cycle of $50 \%$ and this was achieved since $R_{5}$ and $R_{7}$ were ganged and adjusted simultaneously to produce a square-wave signal oscillating at a frequency of $120 \mathrm{~Hz}$. The $120 \mathrm{~Hz}$ signal from the IC4 is further divided by TC4027BP (IC5) to produce a $60 \mathrm{~Hz}$ signal which is very stable since its $120 \mathrm{~Hz}$ source frequency is stable. The reason for this division is to meet the $60 \mathrm{~Hz}$ oscillating frequency required by virtually all electrical and electronics appliances. The driver circuit terminated with a differential amplifier employing two C945 NPN transistors (Q4 and Q5) wired in the common collector configuration (Mottershead, 2005; Jones, 1979) whose outputs serve as the inputs to the IRF150 MOSFET transistors switching sub-circuit.

The switching power of the MOSFET is very critical in this design, since it determines the switching speed in conjunction with the switching speed of Relay A. The MOSFET forces the $24 \mathrm{Vd}$.c from the battery to oscillate at the frequency of the oscillator while increasing the amplitude of the oscillator from $12 \mathrm{~V}$ dc to a new voltage level of $24 \mathrm{Vac}$ through superposition. This $24 \mathrm{Vac}$ (theoretical value) is fed to a step-up transformer (T3) whose ratio of primary to secondary winding is one to ten (1:9.17) respectively. The step-up transformer produces an output voltage of $236.56 \mathrm{~V}$ ac because the batteries voltage was $25.8 \mathrm{Vas}$ at the time of testing the inverter.

Finally, a capacitive-inductive filter circuit consisting of an inductor (L1) and a capacitor (C11) is included to shape and smoothens the square-wave output voltage of transformer T3 to an sine-wave required by virtually all electrical and/or electronic appliances. 


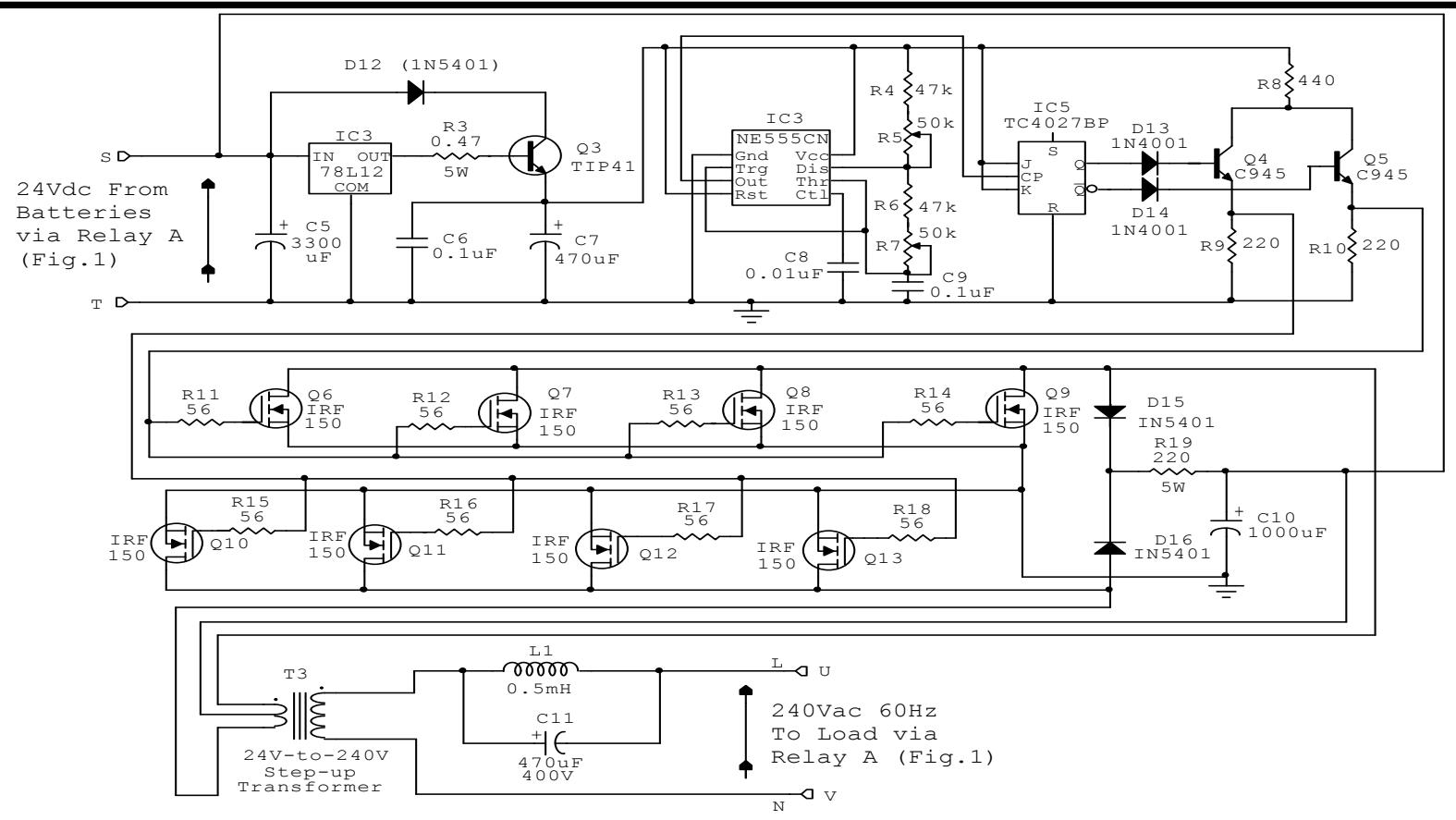

Figure 2: The driver and switching circuit.

\subsection{The Automatic Battery Charger and the Battery Voltage Level Indicator \\ The last two circuits shown in Figure 3 and} Figure 4 are the automatic $30 \mathrm{Vdc}$ battery charger and the battery voltage level indicator respectively. The battery charger designed for this inverter is a high performance charger with self regulating features. The main voltage regulator integrated circuit is the LM338 (IC6) whose output voltage is fixed at $27 \mathrm{~V}$ using the resistors values defined by Eqn.11 below and shown in Figure 3 through transistors Q14 and Q15 wired in the Darlington configuration mode (Franco, 1998; Jones, 1979):

$$
V_{\text {out }}=1.2 \cdot\left(1+\frac{R_{22}+R_{23}}{R_{20}+R_{21}}\right)
$$

The comparator sub-circuit is built around IC8 (LM308A) and transistor Q16. This circuit uses the batteries voltage from the NC terminal (Point $P$ ) of Relay B (Figure 1) as a reference voltage to control the charging of the batteries by comparing the reference voltage $\left(\mathrm{V}_{\text {ref }}\right)$ against the charging voltage $\left(\mathrm{V}_{\text {charge }}\right)$. The batteries charging operation starts when the output of IC8 goes low (OV), transistor Q16 turns OFF and transistor Q14 turns ON. When the batteries are fully charged, the output of IC8 goes high (+27V), Q16 turns ON and Q14 turns OFF. The sensitivity of the comparison action is provided by the potentiometer (variable resistor R29) which determines the ON-OFF switching of Q16.

The comparator sub-circuit is configured, as described in Coughlin and Driscoll, 1989, in such a way that when $V_{\text {ref }}$ is less than $V_{\text {charge }}$, the output of IC8 goes low (0V), Q16 turns OFF and Q14 turns ON to charge the batteries with LED1 ON. When $V_{\text {ref }}$ is equal to or greater than $V_{\text {charge, }}$, the output of IC8 goes high (+27V), Q16 turns ON and Q14 turns OFF to stop the charging process while LED2 turns ON indicating that the batteries are fully charged. The charging current is limited to 2 Amperes for smooth charging of the batteries. The charger switches $\mathrm{ON}$ and starts the charging process when the battery voltage drops below $22.5 \mathrm{~V}$ and switches OFF when the battery voltage reaches $25.5 \mathrm{~V}$. 


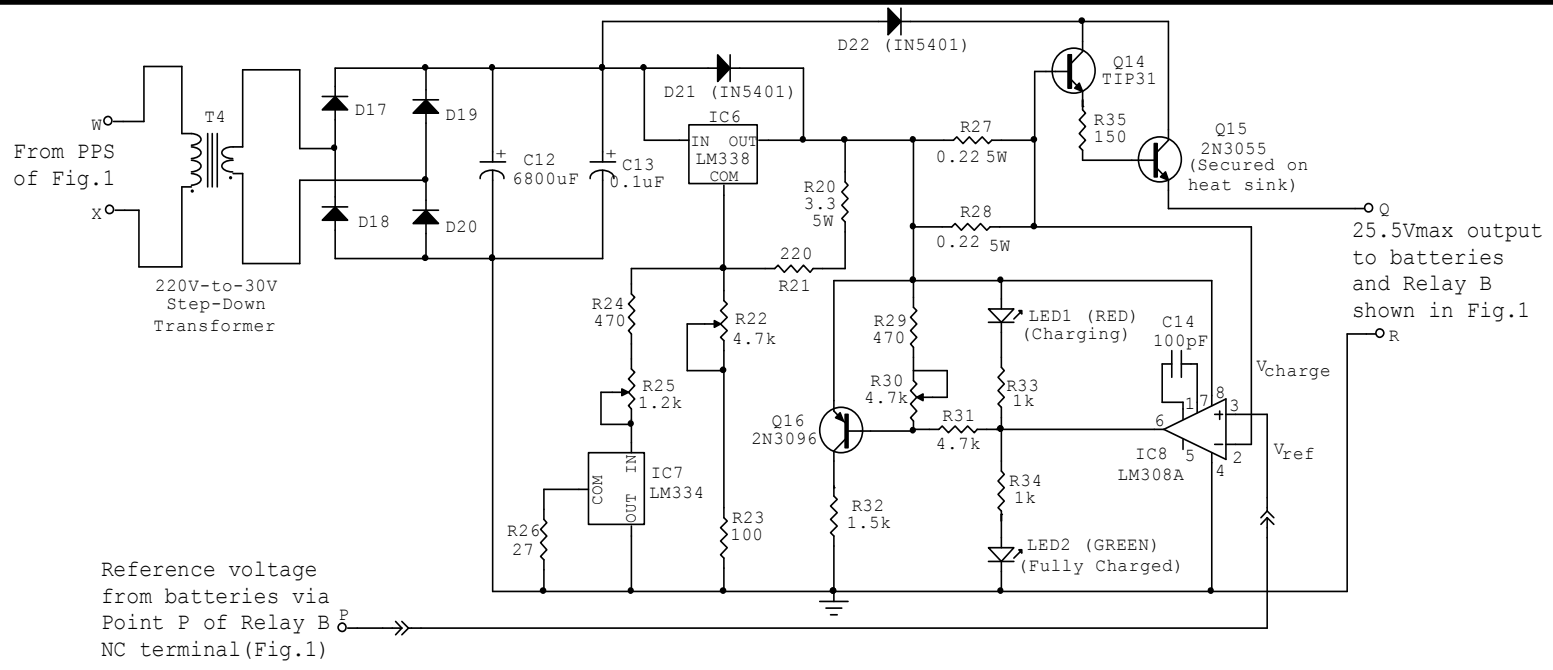

Figure 3. An automatic 24-Volt battery charger.

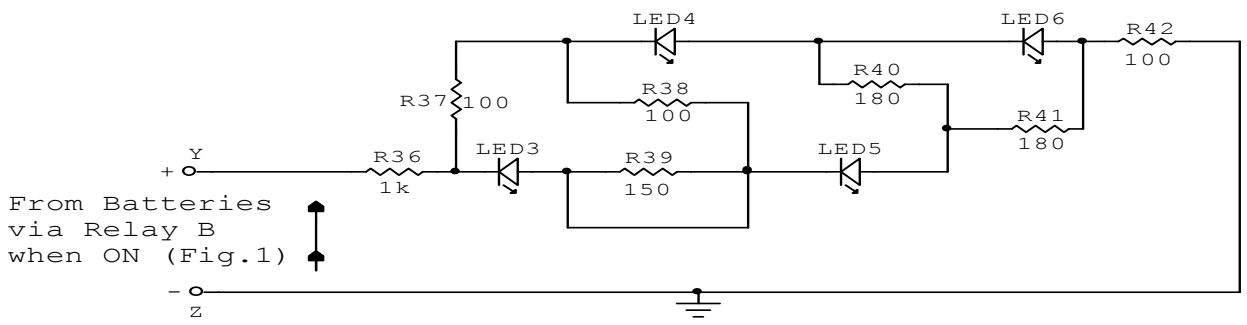

Figure 4. Battery voltage level indicator circuit.

Also included within the battery charger circuit is a temperature compensation circuit built around LM334 (IC7) (Franco, 1998; Melling, 2004), which has been configured to switch OFF the charger when the internal temperature of the entire inverter system is greater than $45^{\circ} \mathrm{C}$ (although it can traditionally withstand a temperature of $70^{\circ} \mathrm{C}$ ) (Hall, 1989; Webb, 2005).

The last major circuit is the battery voltage level indicator shown in Fig.4 and configured in such a way that all four LEDs turns ON when the two batteries are both fully charged but the LEDs begins to switch OFF one after the other starting from LED6 down to LED3 as the battery voltage drops from $24 \mathrm{~V}$ (typical) to OV respectively.

\section{Experiments and Results}

The automatic inverter system designed and constructed in this work was tested in the laboratory under different equipments (loads, in Watts) conditions for its performance evaluation. The equipments used for experimenting and testing the automatic inverter system are presented in Table 1 together with their various power ratings. The power ratings of the selected equipments are accepted by the authors as supplied in Instruction Manuals provided by the equipment's manufacturers and these power ratings are also printed on the equipments(Zbar and Koelker, 2003; Melling, 2004; Webb, 2005; Allan, 2005). Preliminary testing of these equipments using the wattmeter, also give close approximate values to those specified by their manufacturers.
In the first experiment, the equipments listed and shown in Table 1 were combined and set up in the laboratory to obtain different wattage in increasing order as shown in Table 2 and powered using the automatic inverter system. These equipments were put into their normal operation in the laboratory using the inverter system until the batteries supply voltage dropped to $10 \mathrm{~V}$. The time interval between the start of the experiment up to the time at which the batteries voltage dropped to $10 \mathrm{~V}$ was computed and recorded. The experiments were performed on daily basis for nine (9) days. At the end of each day's experiment, the batteries were fully recharged to $25.5 \mathrm{~V}$ within an average of two (2) to two and a half $\left(2 \frac{1}{2}\right)$ hours. The results of the experiments are given in Table 2 from Day 1 to Day 9 together with the loads (in Watt) and their corresponding time duration before the batteries voltage to drop to $10 \mathrm{~V}$.

Using the result of Table 2, the loads (in Watt) are plotted against the approximate time durations (in hours) using MATLAB® as shown in Figure 5 in order to determine the steady output power delivered by the inverter system per hour. The slope of the load-time graph (LT-Slope) is given by:

$$
L T-\text { Slope }=\frac{\Delta P Q}{\Delta Q R}=\frac{1708.0-153.8}{4.70-14.86}=-152.97 \mathrm{~W} / \mathrm{hr}
$$

The experimental result from the slope of (12) shows that the inverter can supply an approximate steady output power of 153 Watts per hour for approximately 13 hours. 
In the second experiment, the inverter system was loaded with a one horsepower 5A 220V induction-type electric motor to verify its suitability for industrial applications as well as the time duration of the process.
When the electric motor was switched ON, the output voltage of the inverter dropped from $236.56 \mathrm{~V}$ to $236.48 \mathrm{~V}$ indicating that the inverter system has a negligible output resistance of about $0.03 \%$

Table 1: Equipments (Loads in Watt) used for testing the automatic inverter system

\begin{tabular}{|c|c|c|}
\hline $\begin{array}{l}\text { Equipment } \\
\text { numbers }\end{array}$ & Equipments (Loads) specifications & $\begin{array}{l}\text { Equipment power } \\
\text { Rating (in Watt) }\end{array}$ \\
\hline 1 & Six (6) 60W soldering irons & $360 \mathrm{~W}$ \\
\hline 2 & $\begin{array}{l}\text { A One Horsepower Reliance }{ }^{\circledR} \text { induction-type electric motor rated } \\
\qquad 5 \mathrm{~A} 220 \mathrm{~V}, 1 \mathrm{HP} \approx 0.75 \mathrm{KW}\end{array}$ & $750 \mathrm{~W}$ \\
\hline 3 & $\begin{array}{c}\text { Four (4) Topward® dual beam oscilloscopes (two HM205-3 of 46W } \\
\text { each and two HM203-4 of 39W each) }\end{array}$ & 170W \\
\hline 4 & Five (5) 12W Topward $®$ digital function generator (Model 8112) & $60 \mathrm{~W}$ \\
\hline 5 & Two (2) sets of Pentium IV Intel® computer system (230W each) & 460W \\
\hline 6 & Four (4) 25W Laboratory power supply units & $100 \mathrm{~W}$ \\
\hline 7 & A 20W fluorescent lamp & $20 \mathrm{~W}$ \\
\hline
\end{tabular}

Table 2: Loads and time duration for different load combinations

\begin{tabular}{|c|c|c|c|}
\hline Experiments & $\begin{array}{c}\text { Equipments combinations } \\
\text { to form higher load power }\end{array}$ & $\begin{array}{c}\text { Loads } \\
\text { (in Watts) }\end{array}$ & $\begin{array}{c}\text { Approximate time } \\
\text { duration (in hours) }\end{array}$ \\
\hline Day 1 & 4 and 7 & 80 & $16: 48$ \\
\hline Day 2 & 3 and 7 & 190 & $14: 45$ \\
\hline Day 3 & 4 and 5 & 510 & $12: 10$ \\
\hline Day 4 & 1 and 5 & 810 & $9: 50$ \\
\hline Day 5 & 2,3 and 6 & 1020 & $8: 20$ \\
\hline Day 6 & $1,2,4,6$ and 7 & 1290 & $6: 30$ \\
\hline Day 7 & $1,2,3,4,6$ and 7 & 1460 & $5: 47$ \\
\hline Day 8 & $1,2,5,6$ and 7 & 1680 & $4: 35$ \\
\hline Day 9 & $1,2,3,4,5,6$ and 7 & 1910 & \\
\hline
\end{tabular}

Table 3: Time duration and voltage consumption by Reliance ${ }^{\circledR}$ 1HP induction-type electric motor

\begin{tabular}{|c|c|c|}
\hline $\begin{array}{l}\text { Time duration } \\
\text { (in hours) }\end{array}$ & $\begin{array}{l}\text { Measured battery d.c. } \\
\text { voltage (in Volt) }\end{array}$ & $\begin{array}{c}\text { Measured inverter a.c. } \\
\text { voltage (in Volt) }\end{array}$ \\
\hline $0: 00$ & 25.50 & 236.48 \\
\hline $0: 30$ & 24.74 & 229.43 \\
\hline $1: 00$ & 23.91 & 221.73 \\
\hline $1: 30$ & 23.12 & 216.17 \\
\hline $2: 00$ & 22.31 & 206.90 \\
\hline $2: 30$ & 21.51 & 199.48 \\
\hline $3: 00$ & 20.72 & 192.15 \\
\hline $3: 30$ & 19.92 & 184.73 \\
\hline $4: 00$ & 19.12 & 177.31 \\
\hline $4: 30$ & 18.32 & 169.90 \\
\hline $5: 00$ & 17.53 & 162.57 \\
\hline $5: 30$ & 16.73 & 155.15 \\
\hline $6: 00$ & 15.93 & 147.73 \\
\hline $6: 30$ & 15.13 & 140.31 \\
\hline $7: 00$ & 14.33 & 132.90 \\
\hline $7: 30$ & 13.54 & 125.57 \\
\hline $8: 00$ & 12.74 & 118.15 \\
\hline $8: 30$ & 11.94 & 110.73 \\
\hline $9: 00$ & 11.15 & 103.40 \\
\hline $9: 30$ & 10.35 & 95.98 \\
\hline $10: 00$ & 9.55 & 88.57 \\
\hline
\end{tabular}




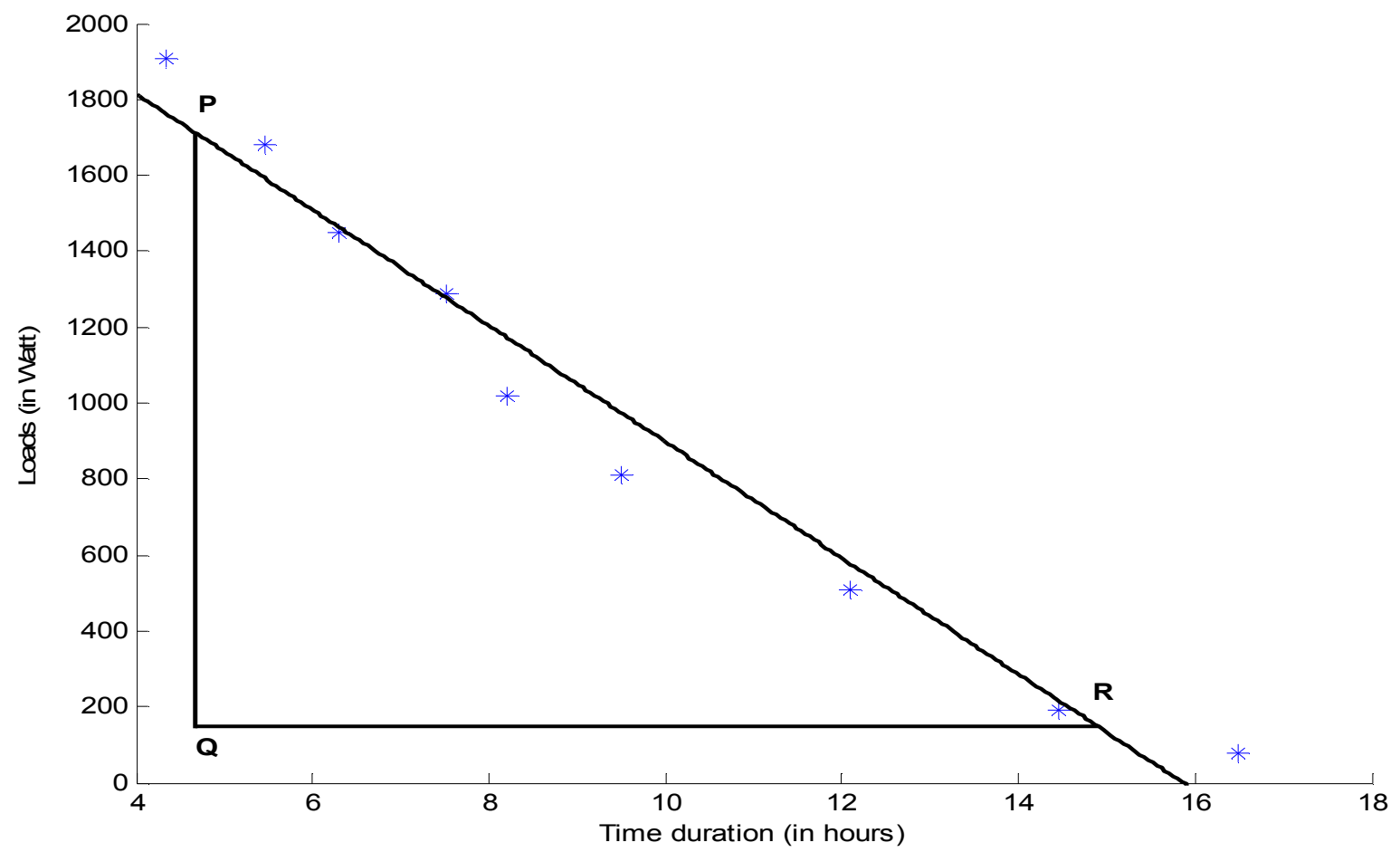

Figure 5. Graph of load power (in Watts) consumption against time duration (in hours)

The batteries voltage and the inverter output voltage during the experiment were recorded every 30 minutes and the results are shown in Table 3 . The result shows the efficiency of inverter system and its suitability for domestic, laboratory and industrial applications.

\section{CONCLUSION AND RECOMMENDATION}

A low cost automatic inverter system capable of converting $24 \mathrm{Vdc}$ to $240 \mathrm{Vac}$ with a power rating of $2000 \mathrm{~W}(2 \mathrm{kVA})$ has been design and constructed with relatively cheap and easily sourced electronics components that are available in local markets. The inverter has been used extensively in the laboratory for several experiments with different equipments of diverse power requirements. However, care was taken not to overload the inverter beyond its maximum power rating of $2000 \mathrm{~W}$ as this could lead to the inverter damage. The inverter system has relatively small output resistance and low power consumption for its circuitries while delivering optimal output power depending on the power requirements of the load.

As a recommendation for further work, the inclusion of a $36 \mathrm{~V}$ dc solar cell panel, stabilized to $27 \mathrm{~V}$, via an additional control circuitry will provide an alternative means of charging the batteries in the absence of public power supply. With this proposed recommendation in the absence of PPS, during day light the batteries will be charged by the solar cell panel while simultaneously supplying energy to the inverter system (if the inverter is in operation). On the restoration of PPS, the charging process will be switched over to the PPS thereby saving the life span of the solar cell panel. This improvement will result in a novel uninterruptible power supply system.

\section{REFERENCES}

Allan, G., 2005. Maplin Electronics. A Product Handbook (Project \& Modules), Maplin Professional System Supplies, UK, pp.372-339.

Chan, T. and Bowler, P., 1974. International Conference on Power Electronics, Power Semiconductors and their Applications", Oct. 7 - 9, pp.237-251.

Coughlin, R. F. and Driscoll, F. F., 1989. Operational Amplifiers and Linear Integrated Circuits. 4th Ed., Prentice-Hall International Edition, New Delhi, India, pp.215-226.

Fitzgerald, A., Higginbothma, D. and Grabel, A., 1994. Basic Electrical Engineering. 5th Ed., McGrawHill International Inc., U.S.A, pp.548-589.

Franco, S., 1998. Design with Operational Amplifier and Analog Integrated Circuits. 2nd Ed., McGrawHill Books Company, Singapore, pp.43-441.

Gottles, M. I., 1985. Power Supplies Switching Regulators Inverters and Converter Circuit. B.P.B publication, New Delhi., India, pp.25-465. 


\section{DESIGN, DEVELOPMENT AND CONSTRUCTION OF A LOW COST AUTOMATIC 2 KVA INVERTER SYSTEM 149}

Hall, D, V., 1989. Digital Circuits and Systems. McGraw-Hill, Singapore, pp.435-557.

Jones, M. H., 1979. A Practical Introduction to Electronic Circuits. Cambridge University Press, London, pp.167-452.

Maris, N., 1980. Electrical and Electronics Principles. Great Britain: Pitman Publishing, pp.1-76.

Melling, T., 2004. RS Catalogue. Enigma Corporation Limited, East Sussex, U.K, pp.989-1882.

Mottershead, A., 2005. Electronic Devices and Circuits. 4th Ed., Prentice-Hall, New Delhi-110001, India, pp.473-517.
Nadon, J. M., 1989. Industrial Electricity. Canada: Delmar publisher Inc., pp.135-198.

Nostrand, V., 1978. Scientific Encyclopedia. 2nd Ed., Van Nostrand Reinhold Company, New York, pp.345-404.

Webb, M., 2005. Farnell Electronics Components limited. Farnell Components, Jerrold Printing, Norwich, pp.1-125.

Zbar, P. B. and Koelker, R. L., 2003. Industrial Electronics: A text-lab manual. 4th Ed., McGraw Hill, Singapore, pp.1-47. 